\title{
DE AANSLIBBINGEN DER SURINAAMSCHE RIVIEREN
}

DOOR

DR. H. VAN CAPPELLE.

Geen ander beeld dan dat, hetwelk ik in de vorige opstellen van het langs de Surinaamsche kust ontwikkeld en zich nog steeds ontwikkelend zeealluvium heb trachten te schetsen, kan wellicht beter geschikt geacht worden om den leek in de geologische wetenschap duidelijk te maken, dat de studie der veranderingen, die wij nog voortdurend aan de aardoppervlakte zien plaats hebben, ons de geologische verschijnselen uit het verleden der aarde moet leeren begrijpen. Het hier bijgevoegde schetskaartje van het uitmondingsgebied der Suriname-rivier zal hem hiervan nog beter kunnen overtuigen.

Dat ook bij eene beoordeeling van terreinen ten behoeve eener eventueele cultuur aan deze studie belangrijke gegevens ontleend kunnen worden, zal een volgend opstel den lezer kunnen leeren, waarin het zeealluvium vergeleken zal worden met gronden, die de rivieren langs hare oevers tot afzetting hebben gebracht, en met de verweeringsprodukten, die nog op hunne primaire ligplaats worden aangetroffen, d. w. z. nog niet van de plaats van hun ontstaan - van het vaste gesteente - zijn afgevoerd.

De vorming van het rivieralluvium zal echter in de eerste plaats de aandacht vragen.

In den loop van iedere rivier kunnen drie gedeelten worden onderscheiden: dc boven- de midden- en de benedenloop.

Het aanzienlijk verval in den bovenloop geeft aan het snelstroomende water een uitschurende kracht in vertikale richting, terwij1 de afzetting van het meêgevoerde gesteentepuin slechts plaatselijk kan optreden.

In den middenloop, waar het verval geringer is, heeft eene in horizontale richting werkende uitschuring plaats, en komen grovere bestanddeelen, die bij hoog water worden aangevoerd, bij laag water tot bezinking. Deze leiden den stroominzijn bedding 


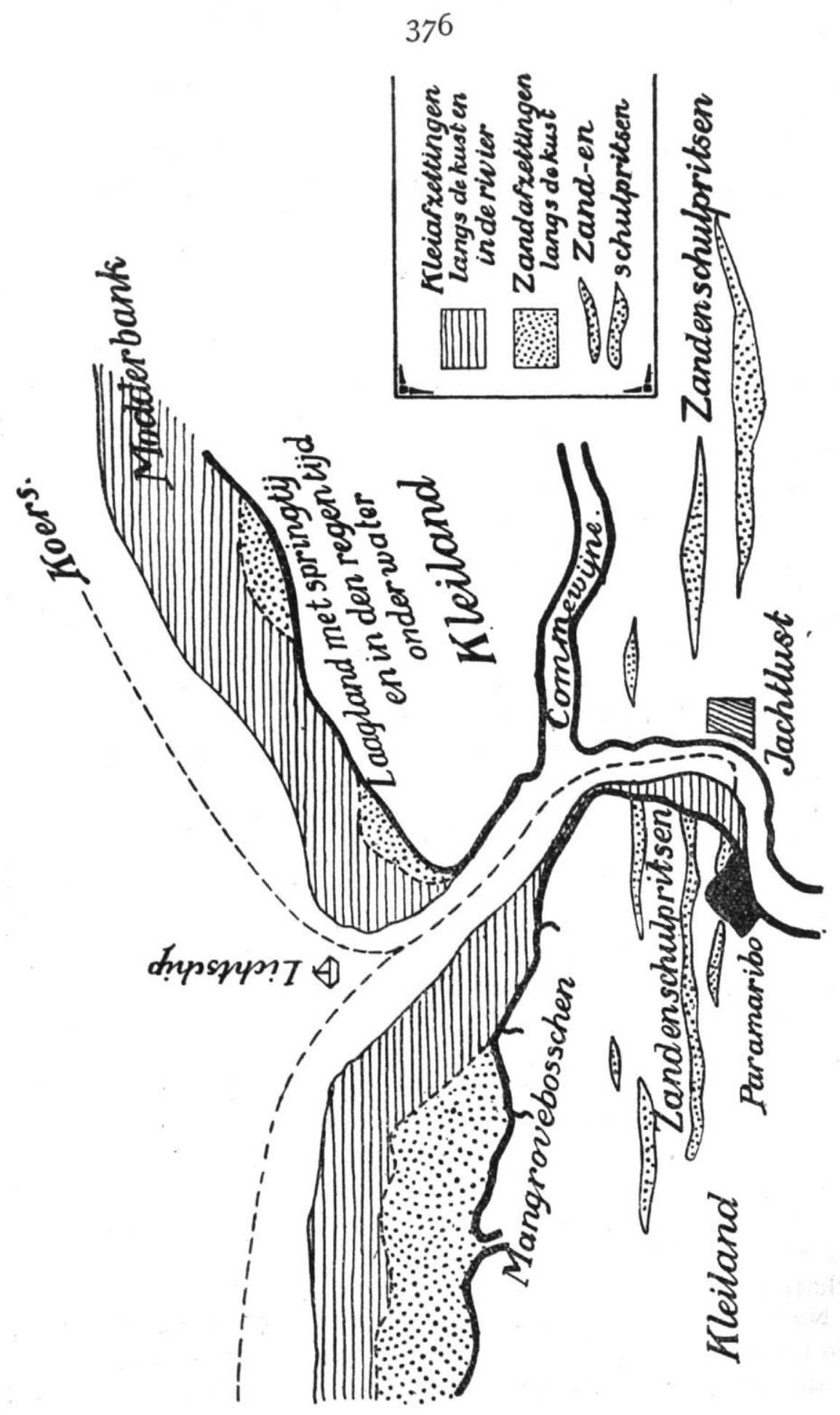


af, waardoor hij gaat slingeren (serpentine- of maeandervorming).

In den benedenloop is het verval eindelijk zóó klein geworden, dat de stroom niet meer in staat is. de uit het bergland aangebrachte verweeringsprodukten verder te voeren. Deze komen hier tot afzetting en alleen een deel van het allerfijnste slib wordt zeewaarts gevoerd.

Alle Surinaamsche rivieren vertoonen in de drie stroomgedeelten een zelfde karakter.

De benedenloop bezit vlakke, door alluviale klei-afzettingen opgebouwde oevers. Maripaen Pinapalmen zijn hier de overheerschende boomgewassen. Krapa en de boschtamarinde komen eveneens veelvuldig voor. Karakteristiek is een oeverplant, de mokko-mokko, die stilstaand water behoeft. Zoover de vloed binnendringt treden nog mangroven en Avicennia'ssporadischop.

In den middenloop, die het z.g. Savannegebied doorstroomt, is eerst het verval nog gering, doch het wordt hoogerop allengs grooter ; het gesteente verschijnt nu en dan boven water, en ten slotte treden enkele stroomversnellingen op. De bedding is vergeleken met den beneden- en den bovenloop over het algemeen smal, terwijl zandheuvels en leemterrassen (die naar den bovenloop toe steeds hooger oprijzen,) de oevers vormen.

Majestueus hoog woud, waartegenover de boomgroei langs den de benedenrivier wel het onderhout der hooglandswouden gelijkt, omzoomt den middenloop der Surinaamsche rivieren. Uit tal van de meest verschillende boomsoorten samengesteld, maakt het den machtigsten indruk aan den concavenoever bij rivierkrommingen, omdat het tegenoverliggende lage zandige terrein aan den Convexen oever een veel ijleren en lageren boomgroei heeft (hier is de boschpapaja, Cecropia peltata $L$. een typische verschijning) en omdat in den drogen tijd de tot de boomtoppen opstijgendeguirlandes van rijk bloeiende klimplanten (Bignoniaceën) de tegenstellling met het statige groene gordijn aan de overzijde nog helpen vergrooten.

Deze groote verschillen in het plantenkleed van beide oevers, die bij opeenvolgende rivierkrommingen den reiziger telkens op nieuw in verrukking brengen, kenmerken vooral het landschap tegenover dat van den boven- en benedenloop.

Niet te verwonderen is het, dat de kostbare houtsoorten, die langs den middenloop meer en meer optreden en van welke in de eerste plaats bruinhart, groenhart, purperhart, barklak, 
bolletrie mogen genoemd worden - in het westen der kolonie nog vermeerderd met Mora of Peto, die hier over groote uitgestrektheden de overhand heeft - reeds zeer vroeg de aandacht getrokken hebben, ook van hen, die niet voor wetenschappelijke doeleinden het binnenland hebben bereisd.

De statige mokko-mokko, in den benedenloop de oeverplant bij uitnemendheid, treedt in den middenloop nog slechts in inhammen op, waar het water niet in beweging is.

Wanneer wij het karakter van den bovenloop der Surinaamsche rivieren, het gebied der watervallen, willen typeeren, mag in de eerste plaats gewezen worden op de afwisseling van over groote lengte zeer breede gedeelten met smalle riviervakken, die aan het terugschrijden van watervallen moeten worden toegeschreven.

Herhaalde stroomvertakkingen geven tot het ontstaan van eilanden aanleiding, wier aantal naar den oorsprong van de rivier toeneemt, en die dikwijls, evenals de oevers, met hoog woud bedekt zijn. Vóór deze eilanden, die de kracht van den stroom breken, hoopt het zand zich in banken op, aan wier vooreinde een krans van statige mokko-mokko's uit het hier onbewogen water oprijst.

Een andere plant in deze stroomverbreedingen lkiest daarentegen juist de heftigst bewogen gedeelten tot standplaats uit. Het is de Mourera fluviatilis Aubl., de karakteristieke verschijning in het gebied der watervallen, waarvan de onder water gedoken bladeren, met sterk gekroesden rand, den indruk van boerenkool maken en wier stijve, afgeplatte aren boven water uitsteken en vaak den wildsten stroom trotseeren.

Deze plant is zeker een van de merkwaardigste voorbeelden van aanpassing aan zeer bijzondere levensomstandigheden.

Terwij1 de aanzienlijke rivierverbreedingen in den bovenloop door lage oevers omzoomd worden en hierdoor en door het optreden van Maripapalmen en Krapa-boomen aan de oevers der benedenrivieren herinneren, hebben de smalle riviervakken in den bovenloop hooge rotsachtige oevers, die hoog woud, vaak gallerij bosch dragen.

Het onderhout van deze wouden in het bergland is rijk aan stekelpalmen (Bactris-soorten) die herhaaldelijk over groote uitgestrektheden in talrijke exemplaren bijeenstaan en dan het „pimpelboesi” der negers vormen. 
In een tropisch land met afwisselende regenperioden en langdurige droge tijden, die in de smalle door hooge oevers ingesloten gedeelten van den middenloop, waar het water niet kan uitwijken, plaatselijke niveauverschillen van Io $\mathrm{M}$. te voorschijn kunnen roepen, zal in de benedenrivier de strijd tusschen zoet en zout water aan periodieke schommelingen onderhevig zijn, want het zeeslib, dat in den drogen tijd op de oevers door den vloedgolf wordt neêrgelegd, kan in de daaropvolgende regenperiode weder gedeeltelijk worden weggespoeld en met rivierbezinkselen overdekt worden. Of wij in dit overgangsgebied met een zeeafzetting, dan wel met een zuiver rivierbezinksel te doen hebben, zal een nauwkeurig bodemonderzoek moeten leeren.

Ook van den benedenloop naar den middenloop is de overgang een geleidelijke. De rivierkrommingen worden, tot wanhoop van den onderzoekingsreiziger, steeds talrijker en scherper; de vette klei langs de benedenrivieren maakt, door het toenemend gehalte van grovere bodembestanddeelen, langzaam voor leem plaats, dat in steeds hooger wordende steile wanden aan de holle oevers bij bochten uit de bedding oprijst, terwijl het zand, dat de bolle oevers bij zulke scherpe bochten bedekt, hier en daar tot heuvelterreinen aangroeit, die het karakter van zandsavannes aannemen - verschijnselen, die allen terug te voeren zijn tot het steeds toenemend verval en het daardoor grooter wordend transporteerend vermogen van den stroom.

Daar niet alleen de vruchtbare alluviale kleigronden in het gebied der benedenrivieren voor den landbouw de aangewezen terreinen zijn, doch ook de hoogere leemterreinen langs haren middenloop voor cultuur in aanmerking komen, komt het mij nuttig voor, alvorens in een afzonderlijk opstel de zeeen rivieraanslibbingen nog nader uit een agronomisch oogpunt te beschouwen, op eenige verschijnselen de aandacht te vestigen, die ons met den arbeid van het stroomende water in het jongste verleden van Suriname's geologische geschiedenis bekend kunnen maken.

Een blik op de kaart leert, dat de sterke slingering (serpentinevorming) aan alle Surinaamsche rivieren eigen is, waar zij het overgangsgebied van het bergland naar het lage alluviale kustgebied, het z.g. Savannegebied, doorsnijden. Het verband tusschen deze op korte afstanden herhaalde sterke verandering 
der stroomrichting en het optreden van leemoevers is zelfs zóó groot, dat reeds de kaart ons kan leeren, dat Loth ${ }^{1}$ ) de grenslijn tusschen de beide genoemde gebieden in het Westen veel te ver zuidwaarts heeft gebogen.

In de Nickerie vangen de leemoevers (eerst nog laag) en de slingeringen boven de Karapana, niet ver van de Cederkreek, aan; in de Maratakka ongeveer op de zelfde breedte, evenals in de Tibiti, rechter zijtak van de Coppename, terwijl zij, in verband met de versmalling der alluviale kuststrook, naar het Oosten der kolonie in dezelfde richting steeds noordelijker optreden. Een vergelijking van den loop dezer rivieren met dien der Paraen der Cottica, die, evenals de Nickerie en de Tibiti, op meerdere plaatsen stroomdoorbraken hebben leeren kennen, kan zulks dadelijkleeren. In de Marowijne, deoostelijkegrensrivier, verschijnen de leemoevers reeds aan de monding der Wanekreek.

Deze slingeringen, vinden haar oorzaak in de grovere verweeringsprodukten, die de rivier bij hoogwater uit het bergland aanvoert, en die, als zij bij laag water bezinken, den stroom in zijne bedding afleiden. Daar hij hierdoor tegen den eenen oever oploopt, brengt hij hier afbrokkeling te weeg (horizontale uitschuring of erosie), en wordt hij teruggeworpen, terwijl hij vervolgens stroomafwaarts tegen den tegengestelden oever aanstoot.

De oorspronkelijk rechte rivier neemt aldus langzamerhand een kronkelend verloop aan en daar de stroomdraad (de vereeniging van alle punten, waar de rivier de grootste snelheid heeft), die in een recht verloopende rivier in het midden ligt, in een slingerenden stroom dichter langs de buitenzijde der bochten loopt, en daar aldus de concave oevers voortdurend ondermijnd worden en zich aan den convexen oever steeds meer gesteentepuin afzet, zullen de kronkels (serpentines) ten slotte zóó sterk worden, dat zij elkander raken.

Het is hier de plaats niet, op dit verschijnsel, dat door den Amerikaanschen geograaf W. M. Davis nauwkeurig bestudeerd is, nader in te gaan. Slechts zij er op gewezen, dat, wanneer de slingeringen haar toppunt hebben bereikt, de rivier, die steeds den weg van het sterkste verval kiest, nu den korteren weg gaat volgen, m. a. w. doorbreekt, en de gevormde bochten eindelijk worden afgesnoerd. In de Nickerie treedt dit verschijn-

I) Kaart van Suriname. Uitgave J. H. de Bussy, Amsterdam I899. 
sel beneden de Arrawarra tweemaal op, en ook in de andere rivieren van Suriname is het geen zeldzaamheid.

Nog een ander verschijnsel treft ons in den middenloop der Surinaamsche rivieren, n. 1. de terrasvormige bouw harer oevers. Daar de rivier steeds streeft naar een normaal profiel, zal zij zich door voortdurenden verlaging der erosiebasis, in hare eigen afzettingen een bedding ingraven, en aldus terrassen te voorschijn roepen, die de overblijfselen zijn harer bezinkselen in een vroeger stadium van de ontwikkeling naar het normaal profiel. In een land, met afwisselende regenseizoenen en langdurige droge tijden, treedt laatstgenoemd verschijnsel sterk op den voorgrond, zoodat bij het bevaren der Surinaamsche rivieren in den drogen tijd, de ontwikkeling van een jong terras aan den voet van het oudere op velen plaatsen zichtbaar wordt. De oudere terrassen vallen niet zoo gemakkelijk in het oog, noch is het gemakkelijk hunne breedte te bepalen, daar zij doorgaans met hoog woud bedekt zijn. De weelderige groei van mais, cassave en vruchtboomen, als lemmetjes en sinaasappelen op de kostgronden van negers, die zich als houtwerkers nu en dan op deze leemterrassen vestigen, doet in de toekomst verwachten, dat uitgestrekte terreinen langs den middenloop van de Surinaamsche rivieren voor de cultuur van tal van gewassen, voor welke de jongere Surinaamsche gronden in aanmerking komen, in gebruik zullen worden genomen ${ }^{1}$ ), nadat winsten zijn gemaakt uit de houtrijkdommen, waarmede zij bedekt zijn.

Bij het bevaren van den middenloop in den drogen tijd trekt nog een belangrijk verschijnsel de aandacht. Onder den soms zes en meer meters uit den waterspiegel van den drogen tijd oprijzenden leemwand, die door afwisseling van vette, lichtblauwe lagen met magere, geelgekleurde lagen, somtijds een laagsgewijzen bouw laat zien, treedt n.l. hoogerop in den middenloop een zandsteen- en conglomeraatbank op, die bij het opvaren des te vroeger voor het eerst wordt waargenomen, naarmate de droge tijdsperiode langer geduurd heeft. ${ }^{2}$ )

1) Reeds in 1854 heeft de landdrost $\mathrm{H}$. van Genderen de aandacht gevestigd op het hooge leemterrein, dat ingesloten wordt door een sterke ombuiging der Nickerie en de als doorbraak gevormde Maniliekreek, omdat het in den grooten regentijd boven het hoogste waterpeil blijft, terwijl de lagere gedeelten voor den rijstbouw uitmuntend geschikt zouden zijn.

2) Beneden de Zonnevischkreek in de Nickerie schijnt de bank ook in den drogen tijd onder water te liggen. 
De voor onderzoekingen gunstige watertoestand in de rivier gaf mij bij de bevaring der Nickerie in Igoo gelegenheid, aan te toonen, dat deze zandsteen niet plaatselijk optreedt, doch overal onder de leemterrassen van den middenloop ontwikkeld is, en dat de korrelgrootte der samenstellende deelen (bijna uitsluitend kwarts, gecementeerd door ijzeroxydhydraat), naar den bovenloop geleidelijk toeneemt, zoodat de zandsteen in conglomeraat of breccie overgaat $\left.{ }^{1}\right)$. Door den sterken stroom langs den hollen oever zijn dikwijls groote blokken van het gesteente losgewoeld en blijkens den vertikalen stand der afwisselende grovere en fijnere lagen voorover in het water gevallen.

De hoogleeraar Martin trof bij zijn reis op de Surinamerivier in 1884 op verschillende punten van den middenloop de zelfde vorming aan, doch kon de samenhang niet vervolgen, daar de bank doorgaans onder water lag.

Evenals dit in de Nickerie het geval is, rust de bank doorgaans op het vaste gesteente, doch is op enkele punten daarvan gescheiden door een laag blauwe klei.

Schomburgk vond dezelfde zandsteenbank langs de Cabalebo, rechter zijrivier van den Corantijn, en meende destijds wegens de gelijkenis van den zandsteen met steenkool zandsteen tot het voorkomen van steenkool te moeten besluiten, een meening, die in Suriname nog steeds blijft nawerken.

Uit al deze waarnemingen blijkt, dat overal in de kolonie de zandsteenbank in den midden'oop der rivieren tot ontwikke'ing is gekomen, en mijn tocht op de Fallawatra, evenals mijn boschtocht door het gebied tusschen de Nickerie en de Coppename heeft mij geleerd, dat ook op de zijrivieren en kreken bij sterke bochten de hooge leemoevers, met onderliggenden zandsteen- en conglomeraatbank, wederkeeren.

Over de geheele kolonie heeft dus in het jongste verleden van de geschiedenis der aarde een zelfden invloed gewerkt, die een grootere stroomsnelheid en een grooter transporteerend vermogen der rivieren ten gevolge had, waardoor in het stroombed veel verder naar het noorden, dan nu het geval is, grof puin (voor het grootste deel kwarts, dat na de totale verweering der silikaatbestanddeelen van de gesteenten overbleef) werd neêrgelegd.

1) Zie blz. 
Het vermoeden ligt voor de hand, dat deze zandsteen- en conglomeraat (of breccie)- bank het overblijfsel is van een ouder terras, waar in de stroom bij het verlagen harer erosiebasis zich eene bedding heeft ingesneden.

De groote moeilijkheden, die de dichte, haast ondoordringbare plantengroei langs de oevers aan het geologisch onderzoek in den weg leg, hebben mij geen zekerheid omtrent dit vermoeden kunnen verschaffen. De door mij tijdens een kampeering op den hoogen linker, leemoever van de Nickerie (beneden de uitmonding der Fallawatra) gedane ontdekking van een meer binnenwaarts gelegen hooger liggend terrein, dat ik uit denzelfden zandsteen opgebouwd vond, stemt met deze meening echter volkomen overeen.

Wanneer wij dus reeds over voldoende gegevens beschikken, om voor den middenloop der Nickerie rivier bovenstaand profiel te mogen aannemen, dan zullen wij het ook, na hetgeen reeds door Martin, Schormburgk en Voltz is waargenomen, voor het geheele riviernet van Suriname geldig mogen verklaren.

Zijn deze leem- en zandsteenterrassen, die een tijdperk van veel grooter stroomsnelheid der rivieren vertegenwoordigen, aan een anderen klimaatstoestand te wijten, zooals de terrassen langs de dalwanden der rivieren van midden-Europa, of moeten zij in verband gebracht worden met een toenmaals nog minder vergevorderden graad van ontblooting (denudatie), dus met een hoogere ligging van het Surinaamsche bergterrein, en daardoor grooter verval der rivieren?

De veel sterkere verweering in het tropisch warme klimaat en de daardoor veel sneller werkende ontblooting van het gebergte, dan in gematigde streken pleiten voor de tweede meening. Klimaatsveranderingen in verband met ijstijden, zooals Europa in den diluviaaltijd heeft gekend, vallen trouwens voor tropische landen buiten beschouwing.

Hetgeen voormaals in het bed van den middenloop der Surinaamsche rivieren plaats vond, n.1. de samenbakking van het aangevoerde gesteentepuin door ijzeroxydhydraat tot zandsteen, conglomeraten en brecciën --al naar de stroom ter plaatse zandkorrels, rolsteentjes of hoekige steenfragmenten aanvoerde - zien wij nu nog in den bovenloop gebeuren. Op talrijke plaatsen in de inhammen en diepten tusschen de rotspartijen in de rivier of ook wel in de drooggelegde kreekbed- 
dingen van het bergland, trof ik dezen zandsteen, conglomeraat of breccie aan, soms in den vorm van gekronkelde worstvormige lichamen, die met een flinken slag met den hamer gemakkelijk van de onderlaag loslieten; ook vond ik meermalen de bedding over eeng groote lengte met dezen zandsteen bedekt.

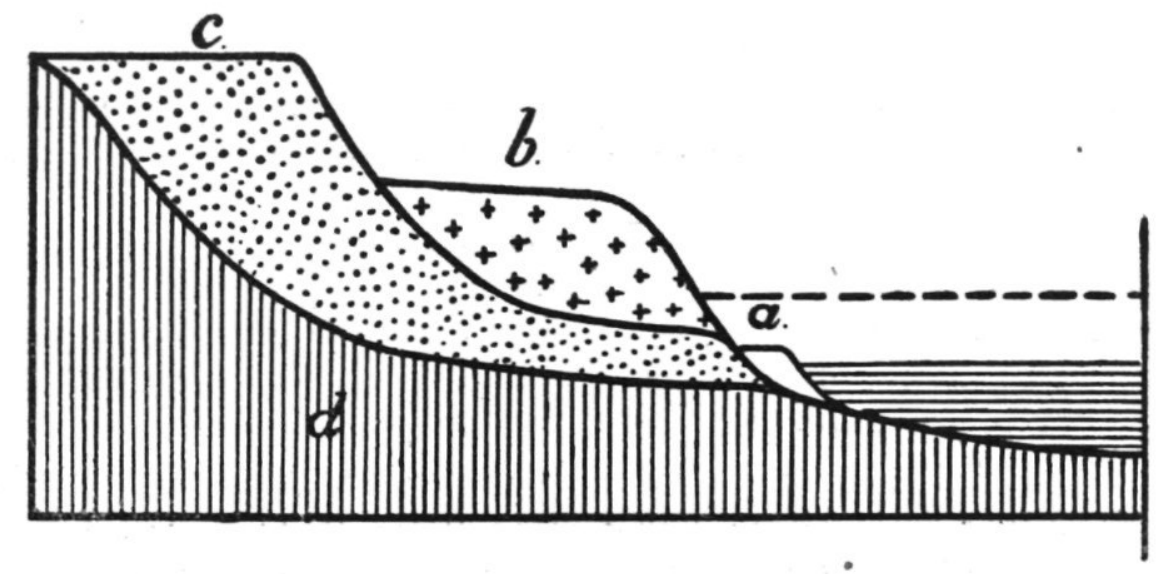

PROFIEL DOOR HET BOVENSTE GEDEELTE VAN DEN MIDDENLOOP DER NICKERIE. a. Tegenwoordig zich op enkele plaatsen vormend teras; $b$. ouder leemteras; $c$. nog ouder zandsteenteras; $d$. vastegesteente. . . . duidt een hoogeren waterstand aan.

Voor den kolonist heeft deze zandsteen alleen in zoover beteekenis, dat, wanneer deze harde, voor water ondoordringbare steenlaag dicht onder de leemoppervlakte ontwikkeld is, deze aanleiding kan zijn tot het ontstaan van leemsavannes, die in den regentijd onder water staan, in den drogen tijd een dor aanzien hebben, en voor den landbouw niet in aanmerking komen.

Van grooter belang voor de economische ontwikkeling der kolonie is daarentegen het veelvuldig voorkomen in den middenloop der Surinaamsche rivieren van porceleinaarde of kaoliën, die nu en dan met het leem der hooge oevers afwisselt en eveneens een aanslibbing is uit een vroegere periode, toen de toestanden andere waren, dan in het tijdperk, dat wij nu beleven.

Dit voor Suriname zoo belangrijk verweeringsprodukt zal in een der volgende opstellen behandeld worden. 